\title{
Phenyl Phthalimide as Corrosion Inhibitor for Corrosion of C-Steel in Sulphuric Acid Solution
}

\author{
I. Zaafarany ${ }^{*}$ \\ Chem. Dept., Faculty of Appl. Sci., Umm Al-qura University, P.O. Box. 118 \\ Makkah Al Mukaramha, Saudia Arabia
}

Received 10 June 2009; accepted 21 October 2009

\begin{abstract}
The effect of some phenyl phthalimide derivatives on the corrosion of carbon steel in $0.5 \mathrm{M} \mathrm{H}_{2} \mathrm{SO}_{4}$ solution was studied using weight loss and galvanostatic polarization techniques. The percentage inhibition efficiency was found to increase with increasing concentration of inhibitor and with decreasing temperature. Inhibition was explained by adsorption of these compounds on the metal surface. The adsorption follows Freundlich adsorption isotherms. Some thermodynamic functions were computed and discussed.
\end{abstract}

Keywords: C-steel corrosion inhibitors, phenyl phthalimide, adsorption.

\section{Introduction}

Carbon steel is used as essential part in the manufacturing of installations used in petroleum and other industries. The use of inhibitors is one of the most practical methods for protection against metallic corrosion, especially in acidic media. Acid solutions are widely used in industry, the most important fields of application being acid picking and industrial acid cleaning. Because of the general aggressively of acid solutions, inhibitors are commonly used to reduce the corrosive attack on metallic materials. Most of the efficient inhibitors used in industry are organic compounds containing nitrogen, sulphur, oxygen atoms and multiple bonds in the molecule through which they are adsorbed on the metal surface [1-10].

The aim of this work is to study the effect of some derivatives of phenyl phthalimide as corrosion inhibitors for dissolution of carbon steel in $0.5 \mathrm{M}$ $\mathrm{H}_{2} \mathrm{SO}_{4}$ solutions using weight loss and galvanostatic polarization measurements. The effect of temperature on the dissolution of $\mathrm{C}$-steel in free and inhibited acid solution and calculation of thermodynamic parameters was also investigated.

\footnotetext{
*Corresponding author. E-mail address: ishaq_zaafarany@yahoo.com
} 


\section{Experimental methods}

The weight composition of the carbon steel type (L-52) is the following: $0.26 \% \mathrm{C}, 1.35 \% \mathrm{Mn}, 0.04 \% \mathrm{P}, 0.05 \% \mathrm{~S}, 0.05 \% \mathrm{Nb}, 0.02 \% \mathrm{~V}, 0.03 \% \mathrm{Ti}$ and the remainder is iron. Carbon steel sheets with double sides surface are of $4 \mathrm{~cm}^{2}$ were used for weight loss measurements, while for the galvanostatic polarization a cylindrical rod embedded in aralidite with an exposed surface area of $0.64 \mathrm{~cm}^{2}$ was used. Before each experiment, the electrodes were polished with different grade emery papers, degreased with acetone, rinsed under running water and finally dried between two filter papers.

The weight loss measurements were carried out as described elsewhere [11]. The anodic and cathodic polarization have been performed with an EG \& G model 173 potentiostat/galvanostat equipment using a platinum fail as the auxiliary electrode. The electrode potential was measured against a saturated calomel electrode (SCE). Details of the experimental procedure, electrolytic cell and electric circuits have been fully described earlier [12].

The percentage inhibition efficiency (\% IE) and a parameter $(\theta)$ which represents the part of the metal surface covered by the inhibitor molecule were calculated using the following equations:

$$
\begin{aligned}
\% \mathrm{IE} & =\left[1-\frac{\mathrm{W}_{\text {add }}}{\mathrm{W}_{\text {free }}}\right] 100 \\
\theta & =\left[1-\frac{W_{\text {add }}}{W_{\text {free }}}\right]
\end{aligned}
$$

where, $\mathrm{W}_{\text {free }}$ and $\mathrm{W}_{\text {add }}$ are the weight loss of $\mathrm{C}$-steel coupon in free and inhibited acid solution, respectively. Also, the percentage inhibition efficiency (\% IE) was calculated from galvanostatic polarization using the following equation:

$$
\% \mathrm{IE}=\left[1-\frac{\mathrm{I}_{\mathrm{add}}}{\mathrm{I}_{\text {free }}}\right] 100
$$

where, $I_{\text {free }}$ and $I_{\text {add }}$ are the corrosion current densities in absence and presence of inhibitors, respectively.

The inhibitors used in this study were selected from phenyl phthalimide derivatives and are listed below:<smiles>[X]c1ccc(N2C(=O)c3ccccc3C2=O)cc1</smiles>

where $\mathrm{x}=\mathrm{NO}_{2}, \mathrm{Cl}, \mathrm{H}, \mathrm{CH}_{3}$ and $\mathrm{OCH}_{3}$ for compounds I, II, III, IV and V, respectively. 


\section{Results and discussion}

\section{Weight loss measurements}

Fig. 1 represents the relation between weight loss of carbon steel coupons and time in $0.5 \mathrm{M} \mathrm{H}_{2} \mathrm{SO}_{4}$ solution in absence and presence of different concentrations of compound $\mathrm{V}$, as an example. Similar curves were also obtained for other compounds (not shown). Inspection of this figure reveals that the linear variation of weight loss with time in inhibited and uninhibited $0.5 \mathrm{M} \mathrm{H}_{2} \mathrm{SO}_{4}$ solutions indicates the absence of insoluble surface films during corrosion, i.e., the inhibitors are first adsorbed on the metal surface and thereafter impede corrosion either by merely blocking the reaction sites (anodic and cathodic) or by altering the mechanism of the anodic and cathodic processes.

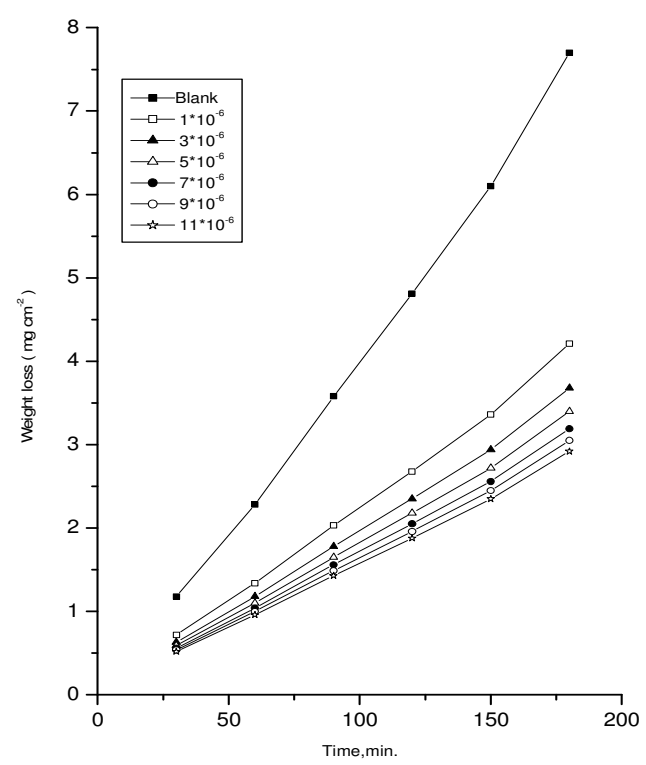

Figure 1. Weight loss- time curves for carbon steel dissolution in $0.5 \mathrm{M} \mathrm{H}_{2} \mathrm{SO}_{4}$ in absence and presence of different concentrations of compound (V) at $303 \mathrm{~K}$.

The inhibition efficiency of these compounds was found to dependent on the inhibitor concentration and the nature of the substituents. The curves obtained in the presence of inhibitors fall significantly below that of free acid. In all cases, the increase in the inhibitor concentration was accompanied by a decrease in weight loss and an increase in the percentage inhibition. These results lead to the conclusion that the compounds under investigation are fairly efficient as inhibitors for C-steel dissolution in $0.5 \mathrm{M} \mathrm{H}_{2} \mathrm{SO}_{4}$ solution.

The calculated values of inhibition efficiencies obtained from weight loss are listed in Table 1. It is obvious that the values of \%IE increase with increasing the inhibitor concentration, whereas decrease in the following order:

Compound V > compound IV > compound III > compound II > compound I. 
Table 1. Inhibition efficiency at different concentrations of inhibitors as determined by weight loss method at $30^{\circ} \mathrm{C}$ and $180 \mathrm{~min}$ immersion.

\begin{tabular}{|c|c|c|c|c|c|}
\hline \multirow{2}{*}{ Inhibitor, M } & \multicolumn{5}{|c|}{ \% IE } \\
\cline { 2 - 6 } & I & II & III & IV & V \\
\hline $1 \times 10^{-6}$ & 35.03 & 38.02 & 41.35 & 45.83 & 46.12 \\
\hline $3 \times 10^{-6}$ & 40.91 & 45.24 & 49.32 & 53.24 & 55.18 \\
\hline $5 \times 10^{-6}$ & 43.22 & 47.92 & 52.82 & 57.46 & 58.33 \\
\hline $7 \times 10^{-6}$ & 45.33 & 49.24 & 55.28 & 60.22 & 61.13 \\
\hline $9 \times 10^{-6}$ & 47.56 & 51.22 & 57.42 & 62.33 & 64.28 \\
\hline $11 \times 10^{-6}$ & 49.22 & 52.33 & 59.26 & 64.66 & 66.44 \\
\hline
\end{tabular}

\section{Synergistic effect of $K I$}

The effect of KI on the inhibitive performance of phenyl phthalimide compounds has been studied using weight loss technique. The values of $\%$ IE for specific concentration of $\mathrm{KI}\left(1 \times 10^{-3} \mathrm{M}\right)$ in the presence of various concentrations of inhibitors are given in Table 2.

Table 2. Inhibition efficiency at different concentrations of inhibitors in presence of $1 \times 10^{-3} \mathrm{M}$ of $\mathrm{KI}$ as determined from weight loss method at $30{ }^{\circ} \mathrm{C}$.

\begin{tabular}{|c|c|c|c|c|c||}
\hline \multirow{2}{*}{ Inhibitor, M } & \multicolumn{5}{|c||}{$\%$ IE } \\
\cline { 2 - 6 } & I & II & III & IV & V \\
\hline $1 \times 10^{-6}$ & 49.32 & 51.32 & 56.22 & 60.11 & 65.17 \\
\hline $3 \times 10^{-6}$ & 54.66 & 56.22 & 58.43 & 63.47 & 72.28 \\
\hline $5 \times 10^{-6}$ & 59.27 & 63.18 & 66.26 & 69.81 & 78.42 \\
\hline $7 \times 10^{-6}$ & 62.36 & 66.82 & 69.12 & 75.12 & 82.12 \\
\hline $9 \times 10^{-6}$ & 68.49 & 72.19 & 74.28 & 79.37 & 88.45 \\
\hline $11 \times 10^{-6}$ & 72.15 & 78.34 & 80.17 & 84.12 & 92.36 \\
\hline
\end{tabular}

The synergistic inhibition effect was calculated using a parameter, $S_{\theta}$, obtained from the surface coverage $\theta$ of the anion, cation and both. Aramaki and Hackerman [13] calculated the synergistic parameter, $S_{\theta}$, using the following equation:

$$
\mathrm{S}_{\theta}=\left(1-\theta_{1+2}\right) /\left(1-\theta_{1+2}\right)
$$

where, $\theta_{1+2}=\left(\theta_{1}+\theta_{2}\right)-\left(\theta_{1} \theta_{2}\right)$.

$\theta_{1}$ is the surface coverage of cation (protonated inhibitor); $\theta_{2}$ is the surface coverage by both the anion $\left(\mathrm{I}^{-}\right)$and the cation (protonated inhibitor).

The calculated values of $S_{\theta}$ are given in Table 3 . They are nearly equal to unity, which suggests that the enhanced inhibition efficiency caused by the addition of 
iodide ions to phenyl phthalimide compounds due to the synergistic effect. The synergistic effect of iodide ions may be due to co-adsorption of iodide ions and additive molecules which may be either competitive or co-operative [14]. The adsorption of iodide ions on the steel surface is the sole responsible factor for the synergism effect of the protonated cation of the inhibitors. The cations of the inhibitors are adsorbed by coulombic attraction on the metal surface where iodide ions are already adsorbed (co-operative adsorption).

Table 3. Synergistic parameter $S_{\theta}$ for different concentrations of all used inhibitors in $0.5 \mathrm{M} \mathrm{H}_{2} \mathrm{SO}_{4}$ in the presence of $1 \times 10^{-3} \mathrm{M} \mathrm{KI}$.

\begin{tabular}{||c|c|c|c|c|c||}
\hline \hline \multirow{3}{*}{ Inhibitor, M } & \multicolumn{5}{|c|}{$\% \mathrm{~S}_{\theta}$} \\
\cline { 2 - 6 } & I & II & III & IV & V \\
\hline $1 \times 10^{-6}$ & 1.02 & 0.98 & 0.96 & 0.92 & 0.96 \\
\hline $3 \times 10^{-6}$ & 1.04 & 0.96 & 0.95 & 0.93 & 0.95 \\
\hline $5 \times 10^{-6}$ & 0.99 & 0.95 & 0.94 & 0.94 & 0.96 \\
\hline $7 \times 10^{-6}$ & 0.98 & 0.94 & 0.92 & 0.95 & 0.94 \\
\hline $9 \times 10^{-6}$ & 0.92 & 0.92 & 0.93 & 0.92 & 0.97 \\
\hline $11 \times 10^{-6}$ & 0.91 & 0.89 & 0.92 & 0.91 & 0.98 \\
\hline \hline
\end{tabular}

\section{Effect of temperature}

The effect of rising temperature on the corrosion rate of carbon steel in free acid and in the presence of different inhibitor concentrations was studied in the temperature range $30-70{ }^{\circ} \mathrm{C}$ using weight loss measurements. Similar curves to Fig. 1 were obtained (not shown). As the temperature increases, the rate of corrosion increases and hence the inhibition efficiency of the additives decreases. Hence, the desorption is aided by increasing the temperature. This behavior proves that the adsorption of inhibitors on C-steel surface occurs through physical adsorption.

The apparent activation energy $\mathrm{E}_{\mathrm{a}}$, the enthalpy of activation $\Delta \mathrm{H}^{*}$ and entropy of activation $\Delta \mathrm{S}^{*}$ for corrosion of carbon steel in $0.5 \mathrm{M} \mathrm{H}_{2} \mathrm{SO}_{4}$ solutions in the absence and presence of different concentrations of phenylphthalimide compounds were calculated from Arrehenius equation [15]:

$$
\mathrm{K}=\mathrm{A} \exp \left(\frac{-\mathrm{E}_{\mathrm{a}}}{\mathrm{RT}}\right)
$$

and from transition state equation

$$
\mathrm{K}=\frac{\mathrm{RT}}{\mathrm{Nh}} \exp \left(\frac{\Delta \mathrm{S}^{*}}{\mathrm{R}}\right) \exp \left(\frac{-\Delta \mathrm{H}^{*}}{\mathrm{RT}}\right)
$$


where $\mathrm{K}$ is the rate of metal dissolution, $\mathrm{A}$ is the frequency factor, $\mathrm{N}$ is Avogadro's number and $\mathrm{R}$ is the universal gas constant.

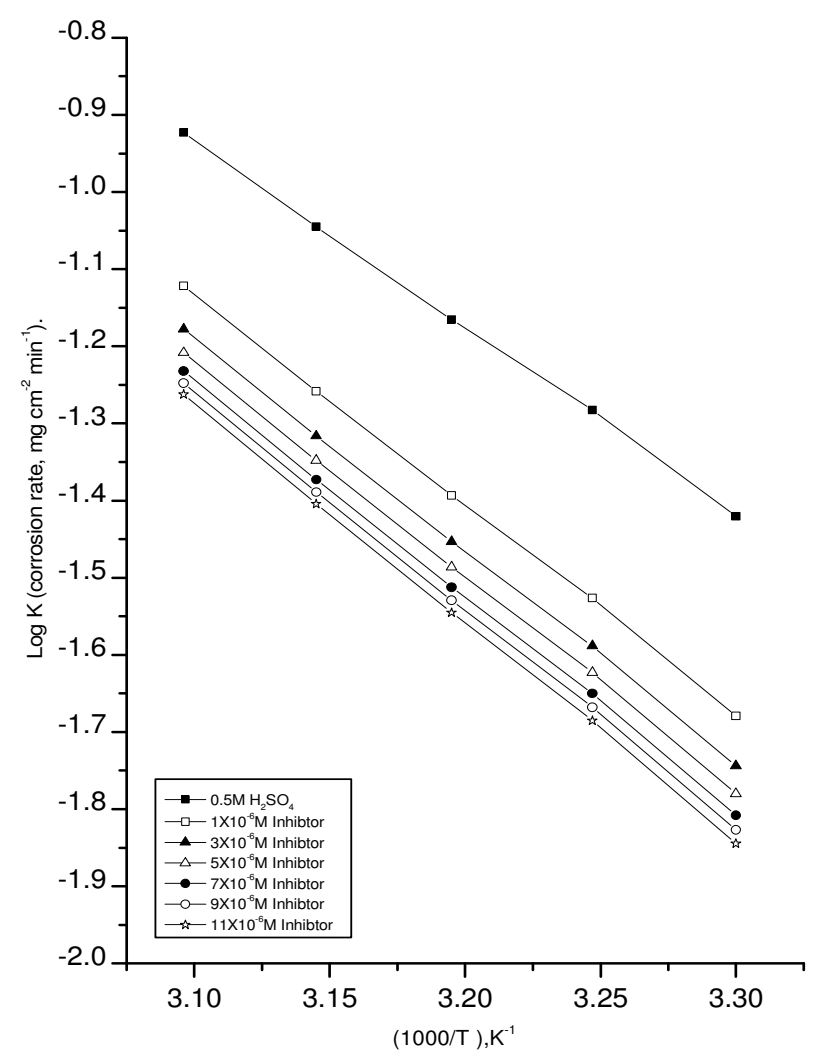

Figure 2. Log corrosion rate vs. $1 / \mathrm{T}$ curves for carbon steel dissolution in $0.5 \mathrm{M} \mathrm{H}_{2} \mathrm{SO}_{4}$ in absence and presence of different concentrations of compound (V).

Fig. 2 represents plot of $\log \mathrm{K}$ against 1/T for C-steel in $0.5 \mathrm{M} \mathrm{H}_{2} \mathrm{SO}_{4}$ solution in absence and presence of different concentrations of compound $\mathrm{V}$, as an example. Similar curves were obtained for other compounds (not shown). Straight lines were obtained with slope equal to $-\mathrm{E}_{\mathrm{a}} / 2.303 \mathrm{R}$. The values of $\mathrm{E}_{\mathrm{a}}$ for corrosion reaction in the absence and presence of different compounds were calculated and are given in Table 4. On the other hand, Fig. 3 represents the plot of $\log \mathrm{K} / \mathrm{T}$ against $1 / \mathrm{T}$ for $\mathrm{C}$-steel in $0.5 \mathrm{M} \mathrm{H}_{2} \mathrm{SO}_{4}$ solution in absence and presence of different concentrations of compound V. Similar curves were obtained for other compounds (not shown). This relation gave straight lines with slope equal to $\Delta \mathrm{H}^{*} / 2.303 \mathrm{R}$ and the intercept is $\log \mathrm{R} / \mathrm{Nh}+(\Delta \mathrm{S} * / 2.303 \mathrm{R})$. The obtained values of $\Delta \mathrm{H}^{*}$ and $\Delta \mathrm{S}^{*}$ are given in Table 4 . 
Table 4. Activation parameters for dissolution of C-steel in absence and presence of different concentrations of inhibitors in $0.5 \mathrm{M} \mathrm{H}_{2} \mathrm{SO}_{4}$.

\begin{tabular}{|c|c|c|c|c|}
\hline \multirow[b]{2}{*}{ Inhibitor } & \multirow[b]{2}{*}{ Conc, $\mathrm{M}$} & \multicolumn{3}{|c|}{ Activation parameters } \\
\hline & & $\begin{array}{c}\mathrm{E}_{\mathrm{a}} \\
\mathrm{KJ} \mathrm{mol}^{-1}\end{array}$ & $\begin{array}{c}\Delta \mathrm{H}^{*} \\
\mathrm{KJ} \mathrm{mol}^{-1}\end{array}$ & $\begin{array}{c}-\Delta \mathrm{S}^{*} \\
\mathrm{Jmol}^{-1} \mathrm{~K}^{-1}\end{array}$ \\
\hline Free $\left(0.5 \mathrm{M} \mathrm{H}_{2} \mathrm{SO}_{4}\right)$ & 0 & 49.64 & 44.82 & 136.32 \\
\hline \multirow{6}{*}{ I } & $1 \times 10^{-6} \mathrm{M}$ & 50.81 & 46.12 & 136.62 \\
\hline & $3 \times 10^{-6} \mathrm{M}$ & 51.17 & 46.28 & 136.98 \\
\hline & $5 \times 10^{-6} \mathrm{M}$ & 52.23 & 46.55 & 137.12 \\
\hline & $7 \times 10^{-6} \mathrm{M}$ & 52.88 & 46.93 & 137.34 \\
\hline & $9 \times 10^{-6} \mathrm{M}$ & 53.12 & 47.12 & 138.22 \\
\hline & $11 \times 10^{-6} \mathrm{M}$ & 53.14 & 47.85 & 138.86 \\
\hline \multirow{6}{*}{ II } & $1 \times 10^{-6} \mathrm{M}$ & 51.24 & 46.33 & 136.98 \\
\hline & $3 \times 10^{-6} \mathrm{M}$ & 51.88 & 46.95 & 137.12 \\
\hline & $5 \times 10^{-6} \mathrm{M}$ & 52.67 & 47.12 & 137.88 \\
\hline & $7 \times 10^{-6} \mathrm{M}$ & 53.18 & 47.48 & 138.24 \\
\hline & $9 \times 10^{-6} \mathrm{M}$ & 53.99 & 48.02 & 138.96 \\
\hline & $11 \times 10^{-6} \mathrm{M}$ & 54.12 & 48.55 & 139.22 \\
\hline \multirow{6}{*}{ III } & $1 \times 10^{-6} \mathrm{M}$ & 51.78 & 46.78 & 137.24 \\
\hline & $3 \times 10^{-6} \mathrm{M}$ & 52.16 & 47.24 & 137.78 \\
\hline & $5 \times 10^{-6} \mathrm{M}$ & 52.98 & 47.94 & 137.99 \\
\hline & $7 \times 10^{-6} \mathrm{M}$ & 53.66 & 48.22 & 138.24 \\
\hline & $9 \times 10^{-6} \mathrm{M}$ & 54.12 & 48.87 & 138.78 \\
\hline & $11 \times 10^{-6} \mathrm{M}$ & 54.96 & 49.02 & 139.22 \\
\hline \multirow{6}{*}{ IV } & $1 \times 10^{-6} \mathrm{M}$ & $\overline{52.04}$ & $\overline{477.04}$ & 137.42 \\
\hline & $3 \times 10^{-6} \mathrm{M}$ & 52.86 & 47.38 & 137.95 \\
\hline & $5 \times 10^{-6} \mathrm{M}$ & 53.12 & 47.98 & 138.22 \\
\hline & $7 \times 10^{-6} \mathrm{M}$ & 54.24 & 48.12 & 138.77 \\
\hline & $9 \times 10^{-6} \mathrm{M}$ & 55.78 & 48.94 & 139.22 \\
\hline & $11 \times 10^{-6} \mathrm{M}$ & 56.02 & 50.32 & 139.98 \\
\hline \multirow{6}{*}{$\mathrm{V}$} & $1 \times 10^{-6} \mathrm{M}$ & $\overline{52.38}$ & $\overline{47.40}$ & 137.87 \\
\hline & $3 \times 10^{-6} \mathrm{M}$ & 53.12 & 47.92 & 138.22 \\
\hline & $5 \times 10^{-6} \mathrm{M}$ & 54.18 & 48.34 & 138.89 \\
\hline & $7 \times 10^{-6} \mathrm{M}$ & 54.98 & 49.06 & 139.22 \\
\hline & $9 \times 10^{-6} \mathrm{M}$ & 55.84 & 49.88 & 139.66 \\
\hline & $11 \times 10^{-6} \mathrm{M}$ & 56.32 & 50.12 & 139.97 \\
\hline
\end{tabular}

Inspection of Table 4 demonstrates that the presence of phenyl phthalimide derivatives increases the values of $E_{a}$, indicating the adsorption of the inhibitor molecules on the metal surface. The values of $E_{a}$ increase with increasing the concentration of inhibitor. This means that the presence of these compounds induces an energy barrier for corrosion reaction and the barrier increases with increasing the concentration of these compounds. The positive shift of $\Delta H^{*}$ reflects that the process of adsorption of the inhibitors on the steel surface is an endothermic process. The values of $\Delta \mathrm{S}^{*}$ in the presence and absence of inhibitors are large and negative. This indicates that the activation complex is the rate 
determining step representing association rather than dissociation, indicating that a decrease in disorder takes place on going from reactants to the activated complex [16].

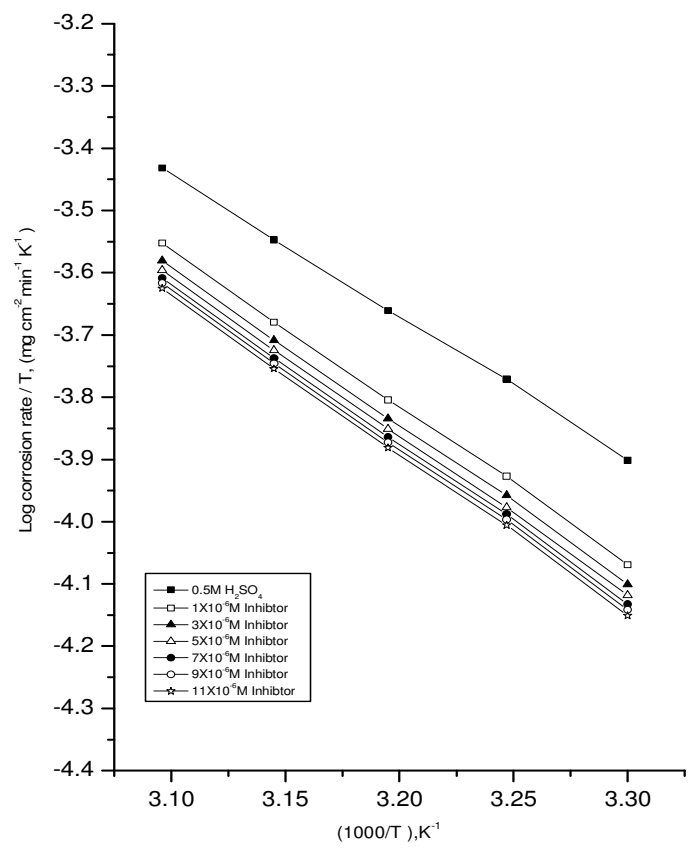

Figure 3. Log (corrosion rate/T)-(1/T) curves for carbon steel dissolution in $0.5 \mathrm{M}$ $\mathrm{H}_{2} \mathrm{SO}_{4}$ in absence and presence of different concentrations of compound (V).

\section{Adsorption isotherm}

The values of the degree of surface coverage $\theta$ were evaluated at different concentrations of the inhibitors in $0.5 \mathrm{M} \mathrm{H}_{2} \mathrm{SO}_{4}$ solution. Attempts were made to fit $\theta$ values to various adsorption isotherms. The Freundlich adsorption isotherm fit the experimental data using the following equation [17]:

$$
\log \theta=\log \mathrm{k}+\mathrm{n} \log \mathrm{C}
$$

where $\mathrm{K}$ and $\mathrm{C}$ represent the equilibrium constant of adsorption process and additive concentration, respectively. A plot of $\log \theta$ against $\log \mathrm{C}$ would give a straight line of intercept $\log \mathrm{K}$. These plots are shown for all compounds in Fig. 4. Linear relationship was obtained for all compounds, suggesting that the Freundlich adsorption isotherm is obeyed. The calculated values for equilibrium constant of adsorption were found to be $(30.25,32.88,36.12,38.55$ and 42.28$) \mathrm{x}$ $10^{-2}$ for compounds I, II, III and IV, respectively.

The equilibrium constant of adsorption $\mathrm{K}$ is related to the standard free energy of adsorption [18] by:

$$
\mathrm{K}=\frac{1}{55.5} \exp \left[\frac{-\Delta \mathrm{G}^{\mathrm{o}}{ }_{\mathrm{ads}}}{\mathrm{RT}}\right]
$$

where $\mathrm{R}$ is the universal gas constant. The value 55.5 is the concentration of water in the solution in $\mathrm{mol} / \mathrm{L}$. 


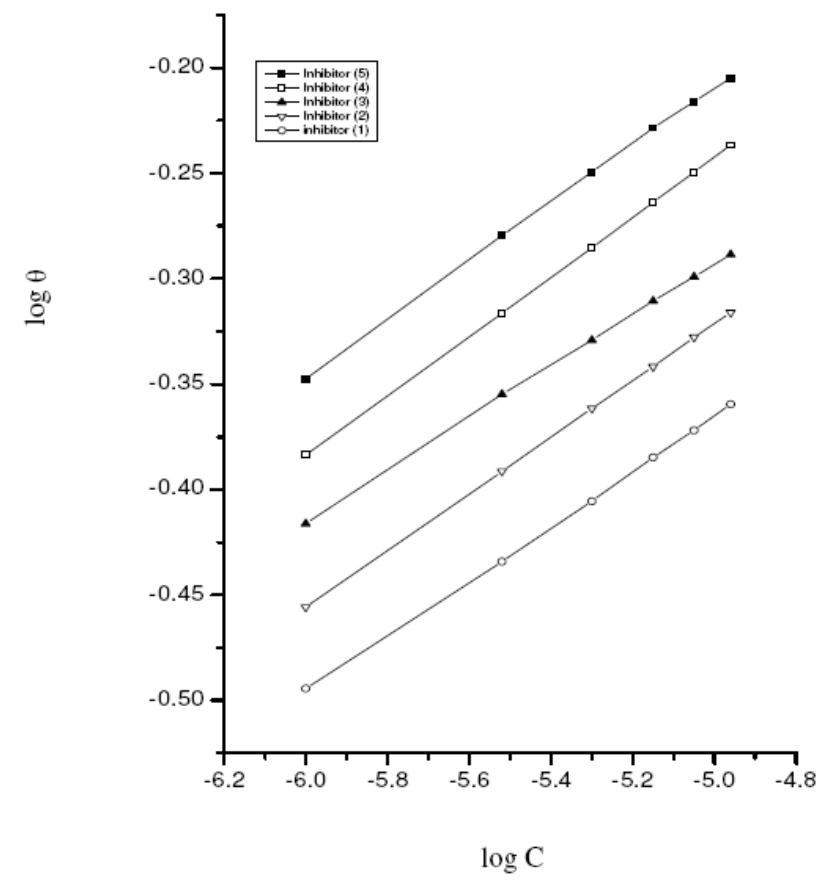

Figure 4. Relation between logarithm of the surface coverage $(\log \theta)$ and logarithm of the inhibitor concentration $(\log C)$.

The values of free energy of adsorption ( $\Delta \mathrm{G}^{*}$ ads $)$ for compounds I, II, III, IV and $\mathrm{V}$ were calculated and found equal to $-3.09,-3.18,-3.29,-3.36$ and $-3.48 \mathrm{KJ}$ $\mathrm{mol}^{-1}$, respectively. The values of $\Delta \mathrm{G}^{*}$ ads are associated with water adsorption/desorption equilibrium which forms an important part in the overall free energy changes of adsorption. It is clear that $\Delta \mathrm{G}^{*}{ }_{\text {ads }}$ increases with the increase of solution energy of adsorbed species, which in turn increase with increasing the size of the molecule [19]. The negative values of $\Delta \mathrm{G}^{*}$ ads obtained here indicate that the adsorption process of these compounds on the steel surface is a spontaneous one.

\section{Galvanostatic polarization}

Fig. 5 shows typical anodic and cathodic polarization curves of C-steel in $0.5 \mathrm{M}$ $\mathrm{H}_{2} \mathrm{SO}_{4}$ in absence and presence of various concentrations of compound $\mathrm{V}$. Similar curves (not shown) were obtained for the other compounds. The values of cathodic $\left(\beta_{\mathrm{c}}\right)$ and anodic $\left(\beta_{\mathrm{a}}\right)$ Tafel constants were calculated from the linear region of the polarization curves. The corrosion current density ( $\mathrm{I}_{\text {corr. }}$ ) was determined from the linear parts of the anodic and cathodic curves with the stationary corrosion potential $\left(\mathrm{E}_{\text {corr. }}\right)$. 


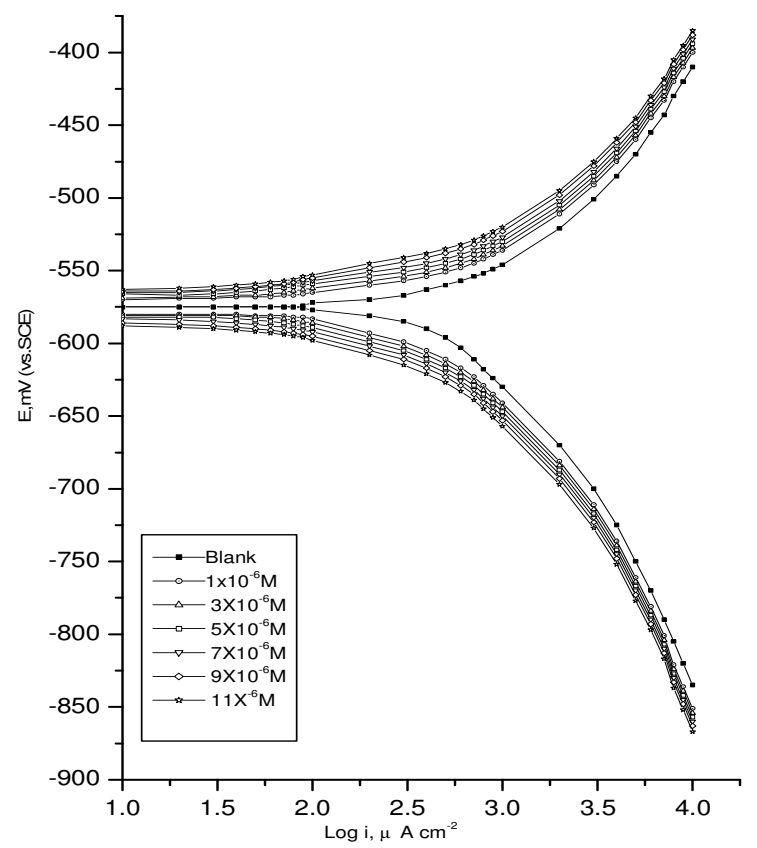

Figure 5. Galvanostatic polarization curves for carbon steel in $0.5 \mathrm{M} \mathrm{H}_{2} \mathrm{SO}_{4}$ in absence and presence of different concentrations of compound (V) at $303 \mathrm{~K}$.

The percentage inhibition efficiency (IE) was calculated using the following equation:

$$
\mathrm{IE}=\left(1-\frac{\mathrm{I}_{\text {corr.add }}}{\mathrm{I}_{\text {corr.free }}}\right) \times 100
$$

where $I_{\text {corr.free }}$ and $I_{\text {corr.add }}$ are the corrosion current densities in the absence and presence of inhibitors, respectively.

Table 5 shows the effect of the inhibitor concentrations on the corrosion kinetic parameters such as $\beta_{\mathrm{a}}, \beta_{\mathrm{c}}, \mathrm{E}_{\mathrm{corr}}, \mathrm{I}_{\text {corr. }}$ and IE. From the results given in Table 5, the following observation could be drawn:

i. the values of $\beta_{\mathrm{a}}$ and $\beta_{\mathrm{c}}$ are approximately constant, indicating the blocking of the available surface area of the metal by the inhibitor molecules. In other words, the adsorbed inhibitor molecule decreases the surface area available for both metal dissolution and hydrogen evolution reaction without affecting the reaction mechanism [19], i.e., these compounds act as mixed inhibitors;

ii. the values of $E_{\text {corr. }}$ change slowly to less negative potential values (i.e. nearly remain constant) and the values of $I_{\text {corr. }}$ decrease. The values of IE increase indicating the inhibiting effect of these compounds;

iii. the values of IE calculated from weight loss and galvanostatic polarization measurements were found to increase with increasing the inhibitor concentration. The inhibition achieved by these compounds decreases in the following order: compound $\mathrm{V}>$ compound IV > compound III > compound II > compound I. 
Table 5. Corrosion parameters for C-steel in free and inhibited $0.5 \mathrm{M} \mathrm{H}_{2} \mathrm{SO}_{4}$.

\begin{tabular}{|c|c|c|c|c|c|c|}
\hline Inhibitor & Conc. & $\begin{array}{c}\mathrm{a} \\
\left(\mathrm{mV} \text { decade }^{-1}\right)\end{array}$ & $\begin{array}{c}\mathrm{c} \\
\left(\mathrm{mV} \text { decade }^{-1}\right)\end{array}$ & $\begin{array}{c}\mathrm{E}_{\text {corr. }} \\
(\mathrm{mV}, \mathrm{SCE})\end{array}$ & $\begin{array}{c}\begin{array}{l}\mathrm{I}_{\text {corr. }} \\
\mu \mathrm{A} / \mathrm{cm}^{2}\end{array} \\
\end{array}$ & $\%$ IE \\
\hline Free & $\left(0.5 \mathrm{M} \mathrm{H}_{2} \mathrm{SO}_{4}\right)$ & 70 & 126 & -576 & 522.0 & - \\
\hline \multirow{6}{*}{ I } & $1 \times 10^{-6} \mathrm{M}$ & 69 & 122 & -576 & 339.3 & 35.00 \\
\hline & $3 \times 10^{-6} \mathrm{M}$ & 67 & 121 & -575 & 07.9 & 41.01 \\
\hline & $5 \times 10^{-6} \mathrm{M}$ & 62 & 123 & -573 & 292.3 & 44.00 \\
\hline & $7 \times 10^{-6} \mathrm{M}$ & 61 & 125 & -570 & 281.8 & 46.02 \\
\hline & $9 \times 10^{-6} \mathrm{M}$ & 62 & 127 & -569 & 271.4 & 48.01 \\
\hline & $11 \times 10^{-6} \mathrm{M}$ & 60 & 130 & -568 & 260.2 & 50.15 \\
\hline \multirow{6}{*}{ II } & $1 \times 10^{-6} \mathrm{M}$ & 76 & 125 & -574 & 318.4 & 39.00 \\
\hline & $3 \times 10^{-6} \mathrm{M}$ & 71 & 124 & -575 & 281.8 & 46.02 \\
\hline & $5 \times 10^{-6} \mathrm{M}$ & 70 & 126 & -573 & 272.6 & 47.78 \\
\hline & $7 \times 10^{-6} \mathrm{M}$ & 68 & 130 & -570 & 255.7 & 51.02 \\
\hline & $9 \times 10^{-6} \mathrm{M}$ & 66 & 133 & -568 & 240.1 & 54.00 \\
\hline & $11 \times 10^{-6} \mathrm{M}$ & 63 & 135 & -566 & 234.2 & 33.13 \\
\hline \multirow{6}{*}{ III } & $1 \times 10^{-6} \mathrm{M}$ & $\overline{70}$ & $\overline{125}$ & $\overline{-573}$ & 307.9 & 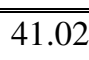 \\
\hline & $3 \times 10^{-6} \mathrm{M}$ & 68 & 125 & -571 & 261.6 & 49.88 \\
\hline & $5 \times 10^{-6} \mathrm{M}$ & 67 & 127 & -570 & 234.9 & 55.00 \\
\hline & $7 \times 10^{-6} \mathrm{M}$ & 66 & 129 & -568 & 224.5 & 57.08 \\
\hline & $9 \times 10^{-6} \mathrm{M}$ & 66 & 130 & -566 & 214.1 & 58.98 \\
\hline & $11 \times 10^{-6} \mathrm{M}$ & 65 & 135 & -563 & 206.8 & 60.54 \\
\hline \multirow{6}{*}{ IV } & $1 \times 10^{-6} \mathrm{M}$ & 65 & 125 & -570 & 281.5 & 46.07 \\
\hline & $3 \times 10^{-6} \mathrm{M}$ & 62 & 127 & -566 & 234.9 & 55.00 \\
\hline & $5 \times 10^{-6} \mathrm{M}$ & 59 & 130 & -563 & 214.2 & 58.96 \\
\hline & $7 \times 10^{-6} \mathrm{M}$ & 59 & 132 & -565 & 198.3 & 62.01 \\
\hline & $9 \times 10^{-6} \mathrm{M}$ & 58 & 135 & -560 & 187.9 & 64.00 \\
\hline & $11 \times 10^{-6} \mathrm{M}$ & 60 & 138 & -555 & 175.5 & 66.38 \\
\hline \multirow{6}{*}{ V } & $1 \times 10^{-6} \mathrm{M}$ & 65 & 124 & -570 & 276.6 & 47.01 \\
\hline & $3 \times 10^{-6} \mathrm{M}$ & 62 & 122 & -568 & 236.9 & 54.62 \\
\hline & $5 \times 10^{-6} \mathrm{M}$ & 60 & 118 & -565 & 219.2 & 58.01 \\
\hline & $7 \times 10^{-6} \mathrm{M}$ & 58 & 120 & -563 & 201.6 & 61.37 \\
\hline & $9 \times 10^{-6} \mathrm{M}$ & 56 & 122 & -560 & 180.8 & 65.36 \\
\hline & $11 \times 10^{-6} \mathrm{M}$ & 59 & 118 & -557 & 170.6 & 67.32 \\
\hline
\end{tabular}

\section{Mechanism of inhibition}

The inhibiting effect of phenyl phthalimide derivatives toward the corrosion of C-steel in $0.5 \mathrm{M} \mathrm{H}_{2} \mathrm{SO}_{4}$ solution may be attributed to the adsorption of these compounds at the metal/ solution interface, where the adsorbed molecule mechanically screen the coated part of the metal surface from the action of the corrodant. The extent of the adsorption of the inhibitor depends on the nature of the metal, the mode of adsorption of the inhibitors and the surface conditions.

The values of inhibition efficiency depend essentially on the electron density at the active centre of the inhibitor molecule. The subsequent step is to follow the effect of the substituted group weather increases or decreases the inhibition 
efficiency through its effect on the active centre, i.e., electron donating or withdrawing groups.

The values of IEs increase with increasing the electro negativity of the substitute. Introduction of nucleophilic (electron donor) substituents leads to an increase of absorbability because of the increase of $\pi$-electron density in the aromatic nucleus. Introduction of electron acceptor substituents has the opposite effect [20].

The substituted groups studied are $-\mathrm{OCH}_{3},-\mathrm{CH}_{3}$, which are located in the phenyl ring. The overlap between the inhibitor electron rich centers and empty d-orbital increases in case of $-\mathrm{OCH}_{3}$ more than $-\mathrm{CH}_{3}$, due to the lone pair of electrons located on the oxygen atom of the $-\mathrm{OCH}_{3}, \mathrm{H}$ atom has no effect on electron density, $\mathrm{Cl}$ and $\mathrm{NO}_{2}$ group are electron withdrawing groups and their order of inhibition depends on the magnitude of their withdrawing character. The order of inhibition efficiency of these compounds from weight loss and galvanostatic polarization techniques decreases in the following order:

$$
-\mathrm{OCH}_{3}>-\mathrm{CH}_{3}>-\mathrm{H}>-\mathrm{Cl}>-\mathrm{NO}_{3}
$$

or

$$
\text { Compound V }>\text { VI }>\text { III }>\text { II }>\text { I }
$$

Compound V has the highest IE; this is due to the presence of $-\mathrm{OCH}_{3}$ group which is an electron repelling group with negative Hammett constant $(\sigma=-0.27)$; this group will increase the electron charge density on the molecule. Compound IV comes after compound $\mathrm{V}$; this is due to the presence of $-\mathrm{CH}_{3}$ group which is an electro donating group with negative Hammett constant $(\sigma=-0.17)$. Also, this group will increase the electron charge density on the molecule, but with lesser amount than $\mathrm{p}-\mathrm{OCH}_{3}$ group in compound $\mathrm{V}$. Compound III with a Hammett constant $(\sigma=0.0)$ comes after compound IV in $\%$ IE because $\mathrm{H}$-atom is $\mathrm{p}$ position has no effect on the charge density on the molecule. Compounds I, II come after compound III in \% IE. This is due to the $-\mathrm{Cl}$ and $-\mathrm{NO}_{2}$ groups which are electron withdrawing groups with positive Hammett constant $\left(\sigma_{\mathrm{Cl}}=+0.23\right.$, $\left.\sigma_{\mathrm{NO} 2}=+0.78\right)$ and their order of inhibition depends on the magnitude of their withdrawing character.

\section{Conclusions}

1. Phenyl phthalimide acts as inhibitor for corrosion of C-steel in $0.5 \mathrm{M} \mathrm{H}_{2} \mathrm{SO}_{4}$ solution.

2. The inhibition efficiency increases with increase in the concentration of these inhibitors, but decreases with an increase in temperature.

3. The inhibition is due to the adsorption of the inhibitor molecule on the steel surface.

4. The adsorption of phenyl phthalimide derivatives on the steel surface follows Freundlich adsorption isotherm.

5. The presence of electro-donating group in the chemical structure of inhibitors increases the values of inhibition of efficiency more than the presence of electro-withdrawing group. 


\section{References}

1. S.A. Abd El-Maksoud, Appl. Surf. Sci. 206 (2003) 129.

2. M.A. Quraishi and R. Sardar, J. Appl. Electrochem. 33 (2003) 1163.

3. $\quad$ S.S. Mahmoud and M.M. Ahmed, Port. Electrochim. Acta 24 (2006) 37.

4. M. Abdallah, A.Y. El-Etre, M.G. Soliman and E.M. Mabrouk, Anti-Corros. Methods and Mater. 53(2) (2006) 118.

5. M. Abdallah, E.A. Helal and A.S. Fouda, Corros. Sci. 48 (2006) 1639.

6. A.A. Al-Sarawy, A.S. Fouda and W.A. Shehab El-Dein, Desalination 229 (2008) 279

7. M.A. Amin, Q. Mohsen and O.A. Hazzazi, Mater Chem. and Phys. 114 (2009) 908.

8. M.R. Arshadi, M.G. Hosseini and M. Ghorbani, Br. Corros. J. 37(1) (2002) 76.

9. M. Ozcan, I. Dehri and M. Erbil, Appl. Surf. Sci. 236 (2004) 155.

10. M. Abdallah, A.S. Fouda, S.A. Shama and E.A. Afifi, African J. Pure Appl. Chem. 2(9) (2008) 83.

11. P.B. Mathur and T. Vasudervam, Corrosion 38(1982) 17.

12. B.G. Ateya, B.E. Anadouli and F.M. El-Nizamy, Bull. Chem. Soc. Japan 54 (1981) 3157.

13. K. Aramaki and N. Hackerman, J. Electrochem. Soc. 116 (1969) 568.

14. A.M. Kunitsugn, W. Hegiwara and H. Nishihara, Corrosion 27(5) (1987) 487.

15. I. Putilova, S. Balezin, I.N. Barannik and V.P. Bishop, Metall. Corros. Inhibit, Pergamon, Oxford, 1960.

16. S.S. Abd El-Rehim, S.A.M. Refaey, F. Taha, M.B. Saleh and R.A. Ahmed, J. Appl. Electrochem. 31 (2001) 429.

17. B. Berge, K. Grijotheim, C. Krohn, R. Neumann and K. Torkiep, Light Metals (edited by S.R. Leavitt), Proceeding of 105th Annual Meeting (1976) 23.

18. M. Kliskic, J. Radosevic and S. Gndic, J. Appl. Electrochem. 27 (1997) 947.

19. K. Khamis and M. Ateya, Corrosion 50(2) (1994) 106.

20. M. Abdallah and H.E. Megahed, Monatshefte für Chemie 126 (1995) 519. 